\title{
MICROESTRUTURA E RESISTÊNCIA À CORROSÃO DE JUNTA SOLDADA DE INCONEL 625*
}

\section{Resumo}

Leandro Brunholi Ramos ${ }^{1}$ Júlio Queiroz Caselani² Leonardo Simoni ${ }^{3}$ Roberto Moreira Schroeder ${ }^{4}$ Célia de Fraga Malfatti ${ }^{5}$

As superligas de níquel apresentam boa combinação de resistência à corrosão e à oxidação, resistência mecânica, resistência à fadiga e à fluência, além de conseguirem operar em temperaturas elevadas, mantendo tais propriedades. A liga Inconel 625 vem sendo estudada como revestimentos, obtidos por cladeamento ou aspersão térmica, para tubos de aços ao carbono utilizados nas indústrias de petróleo e gás. Esses tubos poderão ser unidos pela técnica de soldagem, quando então se obtém uma junta Inconel-Inconel, e isso pode acarretar modificações nas propriedades dessas superligas. O presente trabalho objetiva obter uma junta soldada da liga Inconel 625 empregandose o processo de soldagem a arco utilizando eletrodo revestido Ni-Cr-Mo 3 e caracterizar o cordão de solda quanto à microestrutura, à dureza e à corrosão. A microestrutura foi avaliada por microscopia óptica; para dureza foi realizado perfil de microdureza Vickers ao longo da junta soldada; quanto à corrosão foram realizadas curvas potenciodinâmicas em três diferentes soluções: $3,5 \% \mathrm{NaCl}, 3,5 \% \mathrm{NaCl}+0,01 \mathrm{M}$ $\mathrm{Na}_{2} \mathrm{~S}_{2} \mathrm{O}_{3}$ e $3,5 \% \mathrm{NaCl}+1 \mathrm{~N} \mathrm{H}_{2} \mathrm{SO}_{4}$. Os resultados obtidos mostraram que a zona fundida tem microestrutura dendrítica, sendo a zona afetada pelo calor de aproximadamente 1,2 $\mathrm{mm}$ de extensão. A solda não alterou significativamente as propriedades de corrosão e dureza.

Palavras-chave: Inconel 625; Soldagem; Corrosão; Microestrutura.

\section{MICROSTRUCTURE AND CORROSION RESISTANCE OF WELD JOINT INCONEL} 625

\section{Abstract}

Nickel-based superalloys show a great combination of strength, corrosion, fatigue, creep and oxidation resistance, in addition to the ability of operate in high temperatures. Alloy 625 has been investigated recently like a coating on carbon steel tubes utilized in oil and gas industry utilizing cladding or thermal spray process. These tubes can be joint by welding, however, this process may changes some properties in weld joints InconelInconel. So, the main target of this work is to perform the Inconel 625 weld joint by shielded metal arc welding process with ERCrNiMo-3 and characterize the microstructure, corrosion resistance and hardness. The microstructure was investigated by optical microscopy. Microhardness Vickers profile was done across the joint transverse section. Electrochemical polarization techniques were used to characterize the corrosion resistance in three different solutions: $3.5 \% \mathrm{NaCl}, 3.5 \% \mathrm{NaCl}+0.01 \mathrm{M}$ $\mathrm{Na}_{2} \mathrm{~S}_{2} \mathrm{O}_{3}$ e $3.5 \% \mathrm{NaCl}+1 \mathrm{~N} \mathrm{H}_{2} \mathrm{SO}_{4}$. The results show that fusion zone microstructure is dendritic and the heat input modified the base metal around $1.2 \mathrm{~mm}$. The weld did not significative modification of corrosion resistance and hardness.

Keywords: Inconel 625; Weldment; Corrosion; Microstructure.

1 Engenheiro Metalúrgico, Universidade Federal do Rio Grande do Sul (UFRGS), Porto Alegre, Rio Grande do Sul, Brasil.

Graduando em Engenharia Metalúrgica, UFRGS, Porto Alegre, RS, Brasil.

Engenheiro Metalúrgico, UFRGS, Porto Alegre, RS, Brasil.

Eng. Metalúrgico, Doutor Pesquisador, Departamento de Metalurgia, UFRGS, Porto Alegre, RS, Brasil.

Eng. Metalúrgica, Doutora, Professora Dra., Depto. de Metalurgia, UFRGS, Porto Alegre, RS, Brasil. 


\section{INTRODUÇÃO}

As superligas de níquel foram desenvolvidas por volta de 1930 nos Estados Unidos e eram utilizadas em componentes que necessitavam de alta resistência à corrosão e resistência à fluência. Ao longo dos anos, essas ligas passaram a ser utilizadas em diversas aplicações (turbinas de jatos, motores de foguetes, veículos espaciais, reatores nucleares, submarinos, usinas termoelétricas, equipamento petroquímico, por exemplo) [1], já que apresentam uma boa combinação de resistência à corrosão e à oxidação, resistência mecânica, resistência à fadiga e à fluência. As superligas de níquel são austeníticas, visto que contêm grande quantidade de elementos estabilizadores da fase austenita (níquel). O mecanismo de proteção contra corrosão dessas ligas é semelhante aos dos aços inoxidáveis: formação de um filme passivo de óxido de cromo na superfície da liga. Além disso, essa liga contém majoritariamente, em sua composição, níquel, que é intrinsicamente resistente contra corrosão. A presença de molibdênio (Mo) confere às superligas melhores desempenhos na corrosão localizada tipo pite e tipo fresta [2].

No final da década de 80 , começo dos anos 90 houve um grande número de pesquisas em superligas de níquel devido à aplicação dessas ligas nas indústrias de geração de energia nuclear em reatores de fissão, como paredes de recipientes a vácuo devido sua alta resistência mecânica e baixa condutividade térmica [3]. Entretanto, com a queda da produção de energia nuclear, possivelmente devido ao acidente ocorrido em 1986 na cidade ucraniana de Chernobyl [4], somada ao surgimento de novas ligas e materiais que substituiriam essas superligas de níquel devido seu elevado custo, o uso do Inconel diminuiu nesse setor, reduzindo, consequentemente, as pesquisas científicas dessas ligas.

No entanto, nos últimos anos, a descoberta do pré-sal tem motivado a pesquisa de novas tecnologias para proteção contra corrosão dos dispositivos utilizados para a extração do petróleo e gás. Estudos reportados na literatura propõem revestimentos a base de superligas de níquel, empregando-se o processo de aspersão térmica [5] e de cladeamento [6] como uma alternativa mais barata de proteger contra corrosão os aços ao carbono comumente utilizados pelas indústrias petrolíferas. A liga Inconel 625 apresenta boa resistência contra corrosão em comparação a outras superligas de níquel em solução contendo $\mathrm{CO}_{2}$ e $\mathrm{H}_{2} \mathrm{~S}$ [2], indicando um grande potencial para aplicação em ambientes de exploração de petróleo.

A soldagem está presente em diversas etapas da confecção de componentes metálicos, visto que é um processo de união de metais mais utilizado nas indústrias. Devido ao calor de input para a realização da solda podem ocorrer algumas modificações na microestrutura e propriedades da superliga. A região do metal fundido (MF) apresenta, geralmente, uma microestrutura dendrítica com precipitados interdendríticos, além de conter microsegregação de elementos de liga [7].

O presente trabalho objetiva obter e caracterizar a junta soldada da liga Inconel 625 pelo processo eletrodo revestido quanto à microestrutura, à dureza e à corrosão.

Este estudo tem relação com as indústrias que utilizam juntas soldadas da superliga Inconel 625 como a marítima, a petroquímica, a química, assim como as indústrias petrolíferas que podem usar o processo de cladeamento e de aspersão térmica para aumentar a resistência à corrosão de tubos, visto que os tubos cladeados ou aspergidos necessitam ser soldados uns aos outros, gerando uma junta InconelInconel. 


\section{MATERIAIS E MÉTODOS}

\subsection{Liga de Inconel 625}

Para o presente trabalho foram utilizadas duas chapas da liga Inconel 625 com a dimensão $100 \times 380 \times 11 \mathrm{~mm}$, as quais foram laminadas e posteriormente submetidas a um processo tratamento térmico de recozimento pleno. A Tabela 1 mostra a composição química fornecida pelo fabricante das chapas de Inconel 625 utilizadas neste trabalho.

Tabela 1. Composição química da liga Inconel 625

\begin{tabular}{lllllllllllllll}
\hline Elemento & $\mathbf{C}$ & $\mathbf{S}$ & $\mathbf{C r}$ & $\mathbf{N i}$ & $\mathbf{M n}$ & $\mathbf{S i}$ & $\begin{array}{c}\mathbf{M} \\
\mathbf{0}\end{array}$ & $\mathbf{T i}$ & $\mathbf{N b}$ & $\mathbf{F e}$ & $\mathbf{P}$ & $\mathbf{A l}$ & $\mathbf{C o}$ & $\mathbf{T a}$ \\
\hline$\%$ em peso & 0,023 & 0,001 & 22,3 & 61,04 & 0,04 & 0,13 & 9 & 0,21 & 3,45 & 3,4 & 0,004 & 0,16 & 0,1 & 0,02 \\
\hline
\end{tabular}

\subsection{Soldagem}

Para a realização da solda foi utilizado o eletrodo revestido Ni-Cr-Mo 3 com 3,2 mm de diâmetro e $36 \mathrm{~cm}$ de comprimento, conforme sugerido pela norma $\mathrm{N}-133$ de julho de 2005 da Petrobras [8]. A Tabela 2 mostra a composição química do eletrodo, fornecida pelo fabricante.

Tabela 2. Composição química do eletrodo Ni-Cr-Mo 3

\begin{tabular}{lccccccccccc}
\hline Elemento & $\mathbf{N i}$ & $\mathbf{C}$ & $\mathbf{M n}$ & $\mathbf{F e}$ & $\mathbf{S}$ & $\mathbf{C u}$ & $\mathbf{S i}$ & $\mathbf{C r}$ & $\mathbf{N b}$ & $\mathbf{M o}$ & $\mathbf{P}$ \\
\hline \% em peso & $55 \mathrm{~min}$ & 0,1 & 1 & 7 máx & 0.02 & 0,5 & 0,75 & $20-$ & 3,15 & $8-10,1$ & 0,03 \\
& & máx & máx & & máx & máx & & 23 & - & & \\
& & & & & & & & & & & \\
& & & & & & & & & & &
\end{tabular}

Foi realizada uma solda a arco elétrico de topo e com $60^{\circ}$ de chanfro sem nariz, conforme indica a Figura 1. A amperagem foi entre 65 - 90 A por (corrente) polaridade direta, eletrodo positivo. A solda foi realizada no Laboratório de Soldagem \& Técnicas Conexas da Universidade Federal do Rio Grande do Sul (LS\&TC UFRGS). O eletrodo revestido passou pelo processo de secagem em estufa a $225^{\circ} \mathrm{C}$ por 1,5 horas.

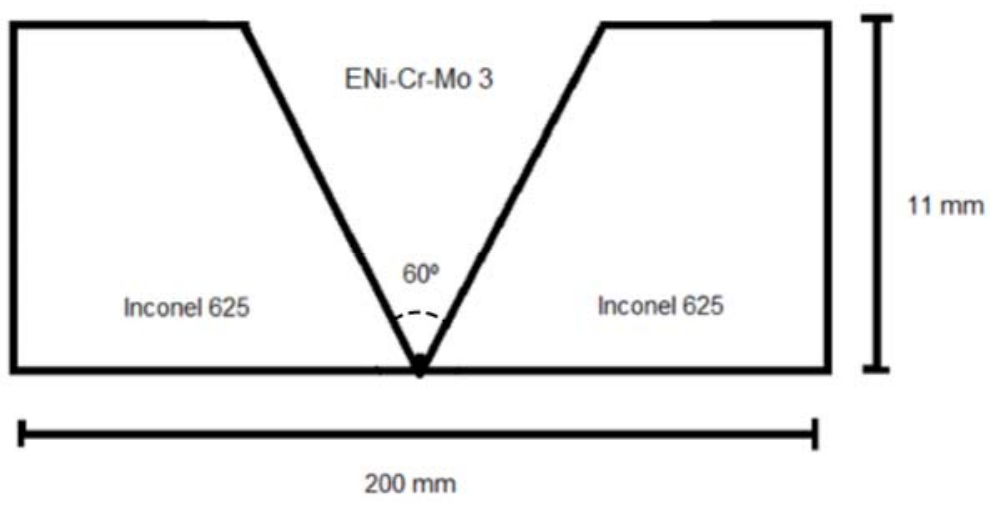

Figura 1. Esquema da solda (fora de escala).

\subsection{Caracterização}

Após obter a junta soldada, amostras de $3 \times 7,5 \mathrm{~cm}$ foram extraídas por meio de corte por jato d'água para que o corte não influenciasse nos resultados posteriores, além dessa liga apresentar alta resistência ao corte. 


\subsubsection{Microestrutura}

As amostras, após o corte, foram embutidas em resina acrílica de forma que a secção transversal da solda pudesse ser estudada. Posteriormente, essa secção transversal foi submetida ao processo de preparação superficial para a realização da metalografia. Houve lixamento com lixas de carbeto de silício de granulometria \#80 a \#2500 de forma gradual e padrão, sendo rotacionada em $90^{\circ}$ à medida que era trocada a lixa, para aumentar a eficiência na retirada dos sulcos oriundos das granulometrias inferiores. Por fim, as mesmas foram polidas em pasta de diamante de $1 \mu \mathrm{m}$ em uma politriz automatizada.

Para revelar a microestrutura, as amostras foram submetidas ao ataque químico com o reativo Adler $(3 \mathrm{~g}$ de cloreto de cobre $\mathrm{II}, 15 \mathrm{~g}$ cloreto ferro $\mathrm{III}, 50 \mathrm{ml}$ ácido clorídrico e água deionizada até completar $100 \mathrm{ml}$ ) por imersão entre 10-15 segundos. Em seguida, as amostras foram analisadas e as imagens registradas utilizando o Microscópio Óptico CX31 do Laboratório de Pesquisa em Corrosão da UFRGS (LAPEC - UFRGS).

\subsubsection{Dureza}

Os ensaios de dureza foram realizados no Laboratório de Metalurgia Física da UFRGS (LAMEF - UFRGS) utilizando o equipamento Durômetro Instron modelo Tukon 2100B. Com este equipamento foi possível realizar o perfil de microdureza Vickers automaticamente ao longo da secção transversal da solda, registrando valores de dureza desde o metal base de um lado da solda até o metal base do lado oposto, passando por toda extensão do cordão de solda.

É importante ressaltar que o corte transversal foi realizado de maneira perfeitamente perpendicular à superfície para se medir as impressões corretas nas amostras, sem acrescentar erros às medidas.

Para as medições de microdureza foi utilizado um indentador Vickers com força de 1 kgf por 15 segundos. A distância entre as indentações foi de 0,4 mm, para que uma impressão não interfira na outra.

\subsubsection{Corrosão}

Para a caracterização quanto à corrosão, foram realizadas polarizações potenciodinâmicas utilizando o equipamento Potenciostático/Galvanostático AUTOLAB PGSTAT 302N no Laboratório de Pesquisa em Corrosão da UFRGS (LAPEC-UFRGS).

Foi utilizada uma célula com três eletrodos: eletrodo de trabalho (metal base ou zona fundida) com $0,1384 \mathrm{~cm}^{2}$ de área exposta, eletrodo de referência (Eletrodo de Calomelano Saturado - ECS) empregando-se um capilar de Luggin e um contra eletrodo (platina). Os ensaios foram realizados em três diferentes soluções: $3,5 \%$ $\mathrm{NaCl}, 3,5 \% \mathrm{NaCl}+0,01 \mathrm{M} \mathrm{Na} 2 \mathrm{~S}_{2} \mathrm{O}_{3}$ e $3,5 \% \mathrm{NaCl}+1 \mathrm{~N} \mathrm{H}_{2} \mathrm{SO}_{4}$. A solução contendo ácido passou pelo processo de borbulhamento de nitrogênio por 2 horas para que o meio fosse desaerado, já as demais soluções foram naturalmente aerado. Todos os ensaios foram sem agitação e à temperatura ambiente, sendo as curvas iniciadas em $-300 \mathrm{mV}$ VS. OCP e terminadas em $+1000 \mathrm{mV}$ VS. OCP com velocidade de varredura de $0,5 \mathrm{mV} / \mathrm{s}$. Os ensaios de corrosão foram realizados em duplicatas.

\section{RESULTADOS E DISCUSSÃO}

A solda Inconel-Inconel utilizando a técnica de soldagem a arco com o eletrodo revestido Ni-Cr-Mo 3 foi obtida com sucesso (Figura 2). O cordão de solda tem de 
aproximadamente 2,0 cm de largura e não apresenta defeitos aparentes na inspeção visual, conforme Figura 2.

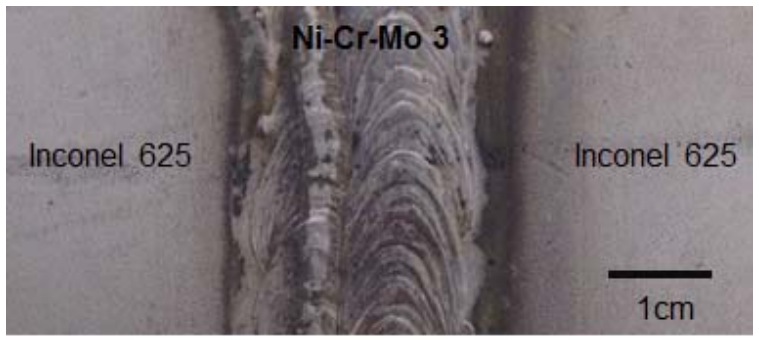

Figura 2. Solda Inconel-Inconel realizada pela técnica de eletrodo revestido (Ni-Cr-Mo 3).

\subsection{Caracterização}

Após a retirada de amostras da junta soldada, foram realizadas caracterizações quanto à microestrutura, a dureza e a corrosão na secção transversal à solda.

\subsubsection{Microestrutura}

A Figura 3 mostra a macrografia e a micrografia da junta soldada realizadas nesse trabalho.

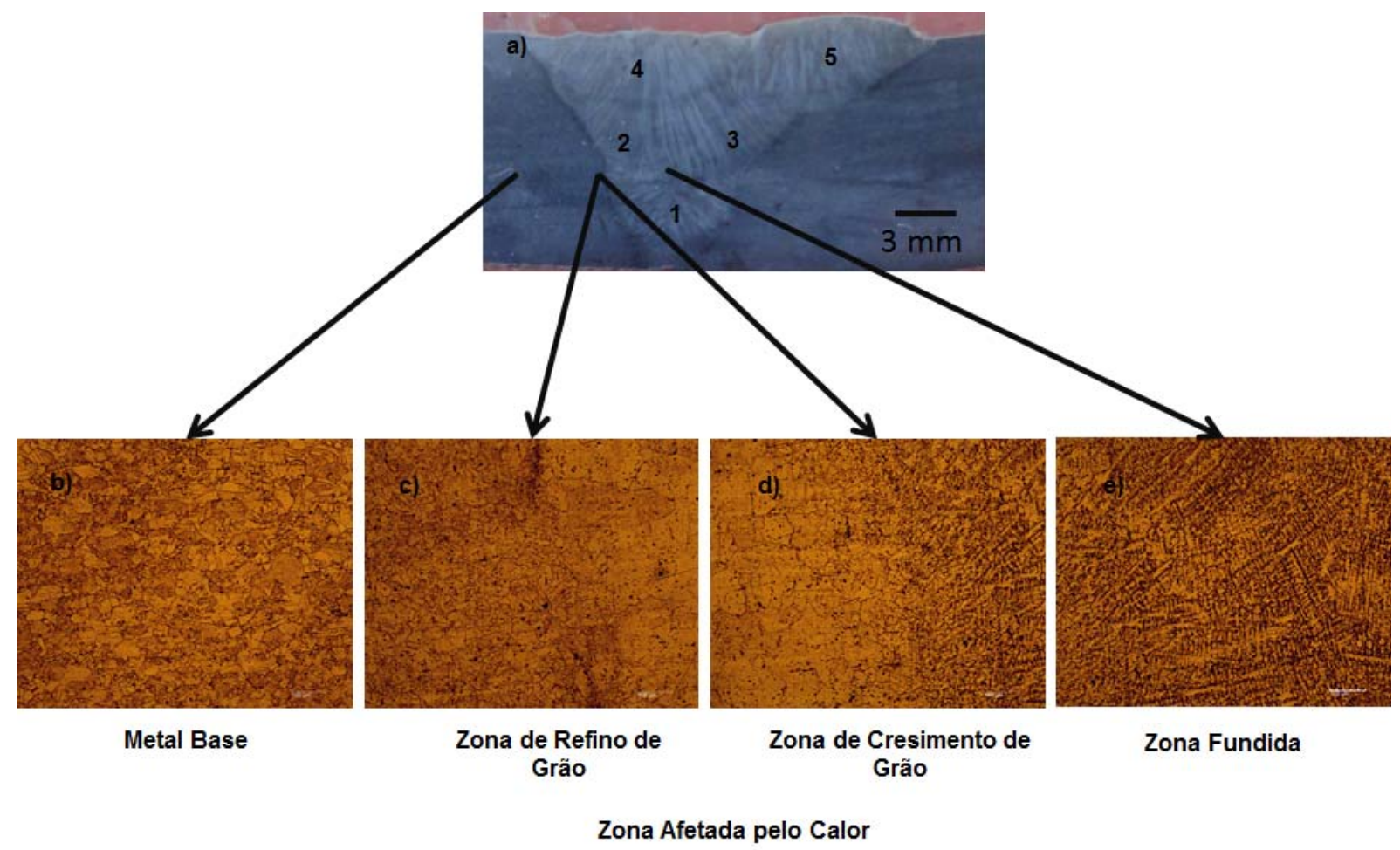

Figura 3. Macrografia e micrografia da junta soldada Inconel-Inconel realizada pela técnica de eletrodo revestido (Ni-Cr-Mo 3). a) macrografia da secção transversal da junta soldada com números indicativos dos passes de soldagem; b) microestrutura do metal base (MB); c) e d) microestrutura da zona afetada pelo calor (ZAC); e) microestrutura da zona fundida (ZF). Ataque químico com reagente Adler.

$\mathrm{Na}$ Figura 3 a) pode-se verificar que foram realizados cinco passes para o preenchimento do chanfro de $60^{\circ}$, marcados pelos números de 1 a 5 . 0 número 1 indica onde ocorreu o primeiro passe, também chamado de passe de raiz. Na macrografia (Figura 3 a)) também é possível observar a estrutura de solidificação 
(dendritas), já que há a fusão e posterior solidificação tanto da alma do eletrodo revestido $\mathrm{Ni}$-Cr-Mo 3 como da liga de Inconel nessa área, devido a diluição típica do processo de soldagem a arco. A micrografia realizada na área de preenchimento (zona fundida), conforme pode ser vista na Figura 3 e), confirma que são dendritas de solidificação.

Para realizar o mapeamento micrográfico de toda a região da junta soldada e os efeitos do calor de input, foram registradas imagens da esquerda (zona fundida na Figura 3 e)) até o metal base (Figura 3 b)). Na Figura 3 d) pode-se observar a primeira região da zona afetada pelo calor (ZAC), zona de crescimento de grão, assim como a zona de ligação da solda. Em direção ao metal base, a Figura $3 \mathrm{c}$ ) mostra a segunda região da ZAC, zona de refino de grão [9]. E por fim, a Figura 3 b) mostra a microestrutura do metal base utilizado neste trabalho. A chapa de Inconel 625 apresenta uma microestrutura (Figura 3 b)) de grãos não grandes nem refinados, além de grãos facetados com algumas maclas, características da fase austenita e do processo de resfriamento que a mesma sofreu.

\subsubsection{Dureza}

Os valores de dureza foram medidos a partir do metal base da extremidade esquerda da amostra até o metal base da extremidade direta da mesma amostra, garantindo que a zona fundida e a zona afetada pelo calor fossem totalmente mensuradas. O perfil obtido é mostrado na Figura 4.

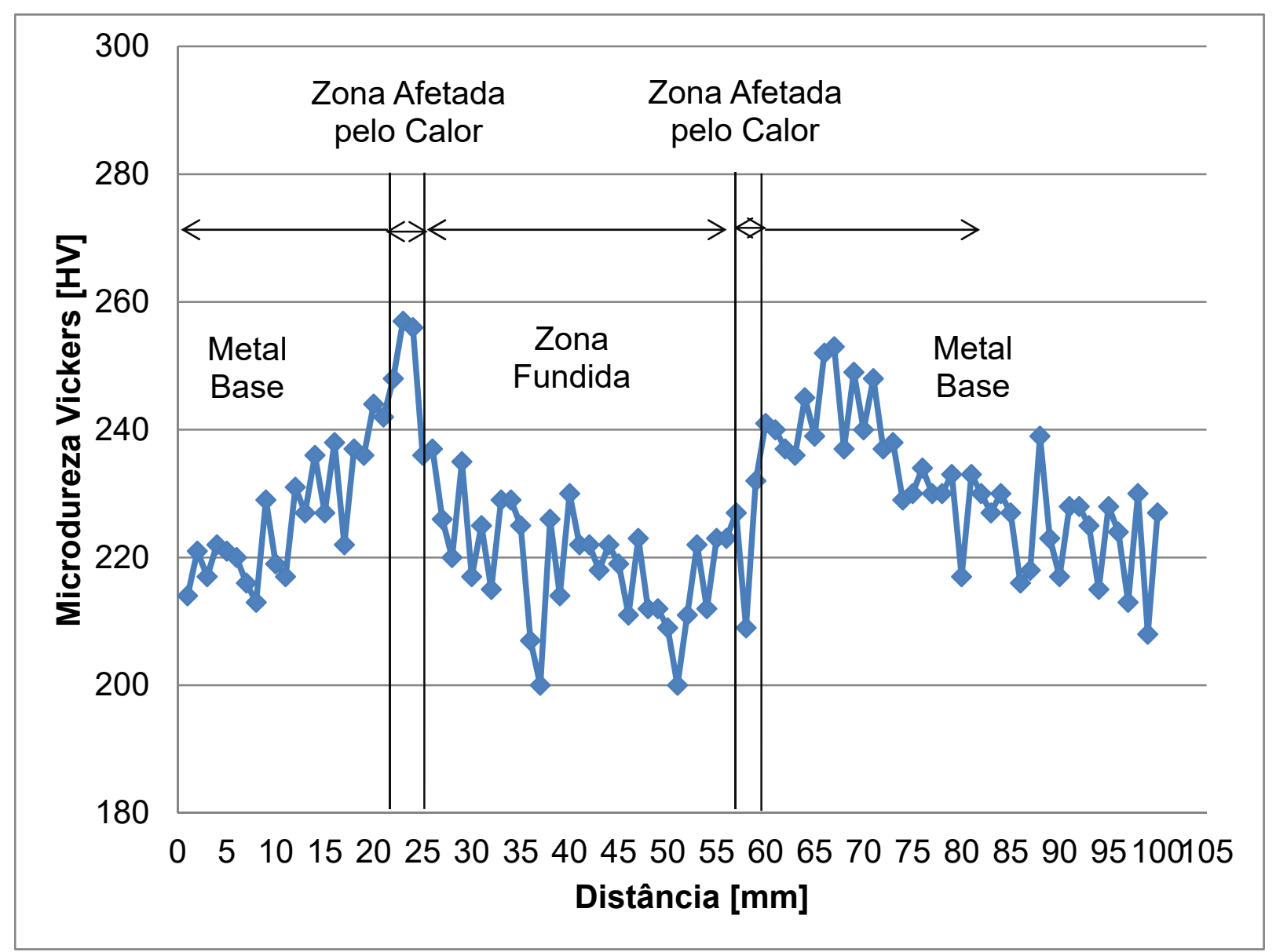

Figura 4. Perfil de dureza. 
O perfil de dureza apresentou um formato de "U" caracterizando que a solda a arco de eletrodo revestido interfere na propriedade de dureza do Inconel 625, porém essa interferência não é expressiva em termos de valores, já que o metal base apresenta uma dureza média de $230 \mathrm{HV}$, enquanto o metal da zona fundida e a zona afetada pelo calor apresentam respectivamente, em média, $219 \mathrm{HV}$ e $240 \mathrm{HV}$, uma diferença de, aproximadamente, $4 \%$ para mais (ZAC) e $4 \%$ para menos (ZF).

O metal base apresenta uma dureza típica de uma chapa de Inconel 625 que sofreu tratamento térmico de recozimento pleno, dando valores próximos, inclusive, aos valores fornecidos pelo fabricante da chapa Philip Corners e CO LTDA. A zona fundida apresenta menores valores de dureza, já que apresenta microestrutura dendrítica (Figura 3 e)), grosseira devido ao fato de ser a estrutura bruta de solidificação. Já a zona afetada pelo calor apresenta os maiores valores de dureza, tendo em vista que é uma região na qual ocorrem modificações estruturais devido ao calor gerado na solda, ocasionando crescimento de grão, refino de grão, formação de precipitados (Figura $3 \mathrm{c}$ ) e d)), aumentando, na média, a dureza naquela região provavelmente na região de refino de grão, juntamente com a presença de precipitados intermetálicos [10].

A Figura 4 colaborou na identificação da extensão da zona afetada pelo calor devido ao input de calor da solda, Juntamente com as micrografias apresentadas na figura 3. Estima-se que a zona afetada pelo calor foi de, aproximadamente, 1,2 milímetros.

\subsubsection{Corrosão}

A Figura 5 apresenta as curvas potenciodinâmicas para duas regiões da junta soldada metal base $(\mathrm{MB})$ e zona fundida $(\mathrm{ZF})$, para os três meios propostos no presente trabalho.

Figura 5. Curvas potenciodinâmicas obtidas em

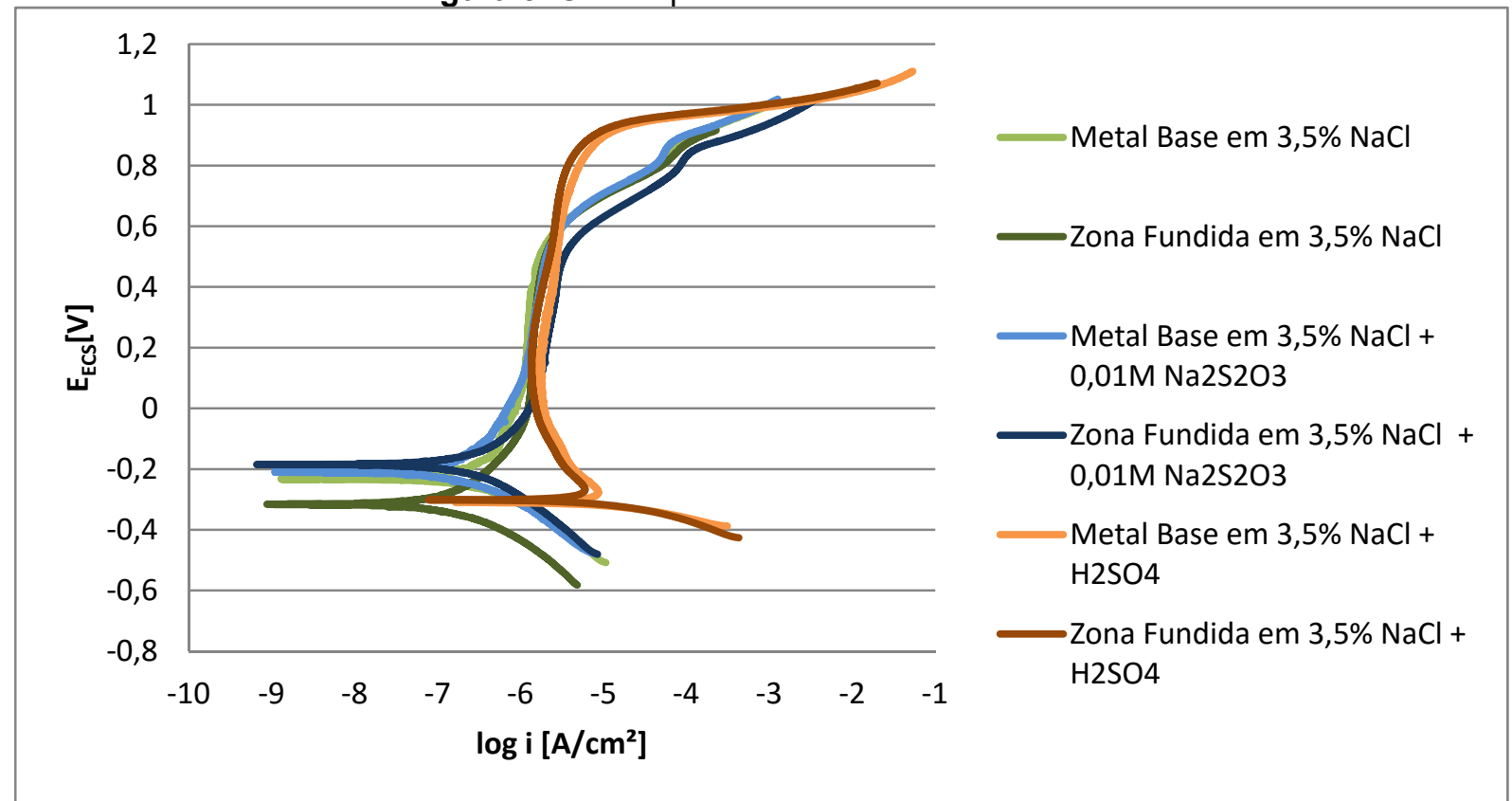

diferentes regiões da solda de Inconel 625 e em diferentes meios. Solução ácida desaerada com nitrogênio por $2 \mathrm{~h}$, e demais soluções em meio aerado. Ensaios sem agitação e à temperatura ambiente. $-300 \mathrm{mV}$ até $+1200 \mathrm{mV}$ VS. OCP com velocidade de varredura de $0,5 \mathrm{mV} / \mathrm{s}$. 
Devido ao grande potencial de aplicação dessas superligas de níquel em ambientes de exploração de petróleo [2], utilizaram-se meios corrosivos contendo cloreto, enxofre e $\mathrm{pH}$ ácido em prol de avaliar o comportamento frente à corrosão da junta soldada em ambientes agressivos desse ramo industrial. A solução ácida $(3,5 \%$ $\mathrm{NaCl}+1 \mathrm{~N} \mathrm{H}_{2} \mathrm{SO}_{4}$ ) foi desaerada para que a reação catódica do oxigênio tivesse sua corrente reduzida, expondo a zona ativa do material nesse meio.

O metal base e a zona fundida apresentaram comportamento similares quanto à corrosão em cada um dos os meios estudados nesse trabalho, demostrando que a zona fundida formada pelo eletrodo Ni-Cr-Mo 3 e o metal de base apresenta excelente resistência à corrosão muito semelhante apresentada pela liga Inconel 625. Mesmo contendo uma microestrutura bruta de fusão (Figura 3 e)), a composição química da alma do eletrodo garante o bom desempenho frente à corrosão quando diluído ao metal de base (zona fundida) nesses meios contendo cloreto, enxofre e $\mathrm{pH}$ ácido. Esse eletrodo vem sendo estudado como revestimento para proteger contra à corrosão de certos aços ao carbono (processo de cladeamente) [6] devido sua excelente resistência à corrosão, mesmo contendo microestrutura dendrítica (Figura $3 \mathrm{e})$ ).

$\mathrm{O}$ meio ácido $\left(3,5 \% \mathrm{NaCl}+1 \mathrm{~N} \mathrm{H}_{2} \mathrm{SO}_{4}\right)$ apresenta os maiores valores de densidade de corrente de corrosão (icorr) tanto para o metal base como para a zona fundida (Figura 5) porque é o meio mais agressivo estudado nesse trabalho, apresentando uma zona de ativação. No entanto, em todos os meio estudados, as correntes passivas foram na ordem de microampère por centímetro quadrado $\left(\mu \mathrm{A} / \mathrm{cm}^{2}\right)$ (Figura 5). $\mathrm{O}$ pH da solução ácida é de 0,34. Nesse meio observa-se uma zona na qual há pronta dissolução de material [11], mostrando a influência do pH baixo.

Já o meio contendo enxofre $\left(3,5 \% \mathrm{NaCl}+0,01 \mathrm{M} \mathrm{Na} \mathrm{S}_{2} \mathrm{O}_{3}\right)$ poderia ser agressivo visto que o enxofre pode alterar a formação do filme passivo obtido nas superligas de níquel [12]. Entretanto, observou-se (Figura 5) que esse meio não alterou as correntes passivas da liga Inconel 625, quando comparado ao meio contendo somente cloreto $(3,5 \% \mathrm{NaCl})$, além de verificar que tanto a solda como o metal base apresentam excelente resistência frente à corrosão pela presença do enxofre. Segundo Mulford e Tromans [12], a presença de tiossulfato em ensaios a temperatura ambiente com solução de $\mathrm{pH}$ neutro não influencia na formação de filmes passivos das superligas de níquel da série 625 devido a presença de molibdênio na liga (Tabela 1).

A partir das curvas potenciodinâmicas (Figura 5) não foi possível identificar corrosão localizada por pite. No potencial de, aproximadamente, $940 \mathrm{mV}$, em meio ácido $\left(3,5 \% \mathrm{NaCl}+1 \mathrm{~N} \mathrm{H}_{2} \mathrm{SO}_{4}\right)$, houve crescimento da corrente caracterizado pela evolução de oxigênio. Esse aumento brusco de corrente devido a evolução de oxigênio também foi observado nas demais soluções, porém no potencial de equilíbrio da reação do oxigênio muda para, aproximadamente, $590 \mathrm{mV}$, tendo em vista o $\mathrm{pH}$ destas soluções $\left(3,5 \% \mathrm{NaCl}, 3,5 \% \mathrm{NaCl}+0,01 \mathrm{M} \mathrm{Na} \mathrm{S}_{2} \mathrm{O}_{3}\right)$ que é 6,5.

\section{CONCLUSÃO}

Com os resultados expostos no presente trabalho conclui-se que a técnica de soldagem utilizando eletrodo revestido $\mathrm{Ni}-\mathrm{Cr}-\mathrm{Mo} 3$ pode ser empregada satisfatoriamente na soldagem do Inconel 625 , já que não afetou a resistência à corrosão original da liga, e alterou de maneira pouco significativa suas propriedades mecânicas, representadas nesse trabalho pelas medidas de dureza. A zona fundida apresentou microestrutura dendrítica bruta de solidificação e a zona afetada pelo 
calor, apresentou pequena extensão mostrando região de crescimento e de refino de grãos, devido ao calor gerado durante o processo de soldagem. A dureza do metal base foi de $230 \mathrm{HV}$, sendo que essa propriedade foi levemente alterada pelo processo de soldagem fazendo com que a zona afetada pelo calor apresentasse valor de dureza de $240 \mathrm{HV}$ enquanto a zona fundida apresentou valor de $219 \mathrm{HV}$. Estima-se que o calor afetou aproximadamente $1,2 \mathrm{~mm}$ do metal base. O metal fundido depositado a partir do eletrodo $\mathrm{Ni}-\mathrm{Cr}-\mathrm{Mo} 3$, conjuntamente à diluição com metal de base, apresentou resistência à corrosão próxima à liga Inconel 625 em todos os meios estudados, possibilitando uma solda Inconel-Inconel de excelente resistência à corrosão.

\section{Agradecimentos}

Os autores agradecem apoio financeiro das agências governamentais brasileiras CAPES (Conselho de Aperfeiçoamento do Pessoal de Nível Superior) e CNPq (Conselho Nacional de Desenvolvimento Científico e Tecnológico).

\section{REFERÊNCIAS}

1 Infomet. "Handbook de Metais \& Ligas | Níquel". Cap. 1 - Desenvolvimento, Propriedades e Aplicações das Superligas de Níquel. Disponível em: http://www.infomet.com.br/site/metais-e-ligas-conteudo-ler.php?codAssunto=72. Acesso em: 09 de março de 2016.

2 Yin ZF, Zhao WZ, Lai WY, Zhao XH. Electrochemical behaviour of Ni-base alloys exposed under oil/gas field environments. Corrosion Science. 2009; 51:1702-1706.

3 Hasiguti RR, Tomabechi K. The materials aspects of the jt-60 device. Journal of Nuclear Materials. 1985; 123:1099-1106.

4 O acidente em Chernobyl. "25 anos do desastre de Chernobyl: mitos e verdades da energia atômica". Disponível em: http://www.tecmundo.com.br/energia/9897-25-anosdo-desastre-de-chernobyl-mitos-e-verdades-da-energia-atomica.htm. Acessado em 08 de março de 2016.

$5 \quad$ Niaz A, Khan SU. A Comprehensive Pitting Study of High Velocity Oxygen Fuel Inconel 625 Coating by Using Electrochemical Testing Techniques. Journal of Materials Engineering and Performance. 2016; 25(1):280-289

6 Xu LY, Li M, Jing HY, Han YD. Electrochemical Behavior of Corrosion Resistance of X65/Inconel 625 Welded Joints. International Journal of electrochemical science. 2013; 8:2069-2079.

7 DuPont JN. Solidification of an alloy 625 weld overlay. Metallurgical and Materials Transactions A. 1996; 27(11):3612-3620.

8 PETROBRAS N-133. CONTEC SC-28. 2005; Soldagem (2 ${ }^{\mathrm{a}}$ Emenda). [acesso em 14 mar. 2016]. Disponível em http://sites.petrobras.com.br/CanalFornecedor/portugues/pdf/N-2033.pdf.

9 Kuo TY, Lee HT. Effects of filler metal composition on joining properties of alloy 690 weldments. Materials Science and Engineering A. 2002; 338: 202-212.

10 Ramkumar KD, Mithilesh P, Varun D, Reddy ARG, Arivazhagan N, Narayanan S, Kumar KG. Characterization of Microstructure and Mechanical Properties of Inconel 625 and AISI 304 Dissimilar Weldments. ISIJ International. 2014; 54(4): 900-908.

11 Piron DL, Koutsoukos EP, Nobe K. Corrosion Behavior of Nickel and Inconel in Acidic Chloride Solutions. Corrosion. 1969; 25(4):151-156

12 Mulford SJ, Tromans D. Crevice Corrosion of Nickel-Based Alloys in Neutral Chloride and Thiosulfate Solutions. Corrosion Science. 1988; 44(12): 891-900. 